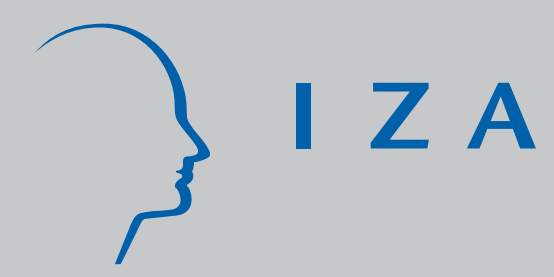

IZA DP No. 107

Fast Track or Failure: A Study of the Completion Rates of Graduate Students in Economics

J an C. van Ours

Geert Ridder

J anuary 2000 


\title{
Fast Track or Failure: A Study of the Completion Rates of Graduate Students in Economics
}

\author{
Jan C. van Ours \\ CentER for Economic Research, University of Tilburg, \\ Institute for Labor Studies (OSA), CEPR and IZA \\ Geert Ridder \\ The John Hopkins University, Baltimore
}

Discussion Paper No. 107
January 2000

IZA

P.O. Box 7240

D-53072 Bonn

Germany

Tel.: +49-228-3894-0

Fax: +49-228-3894-210

Email: iza@iza.org

This Discussion Paper is issued within the framework of IZA's research area General Labor Economics. Any opinions expressed here are those of the author(s) and not those of the institute. Research disseminated by IZA may include views on policy, but the institute itself takes no institutional policy positions.

The Institute for the Study of Labor (IZA) in Bonn is a local and virtual international research center and a place of communication between science, politics and business. IZA is an independent, nonprofit limited liability company (Gesellschaft mit beschränkter Haftung) supported by the Deutsche Post AG. The center is associated with the University of Bonn and offers a stimulating research environment through its research networks, research support, and visitors and doctoral programs. IZA engages in (i) original and internationally competitive research in all fields of labor economics, (ii) development of policy concepts, and (iii) dissemination of research results and concepts to the interested public. The current research program deals with (1) mobility and flexibility of labor markets, (2) internationalization of labor markets and European integration, (3) the welfare state and labor markets, (4) labor markets in transition, (5) the future of work, (6) project evaluation and (7) general labor economics.

IZA Discussion Papers often represent preliminary work and are circulated to encourage discussion. Citation of such a paper should account for its provisional character. 
IZA Discussion Paper No. 107

January 2000

\section{ABSTRACT \\ Fast Track or Failure: A Study of the Completion Rates of Graduate Students in Economics}

This paper presents an analysis of the failure and completion rates of graduate students in economics at three universities in The Netherlands. We find that an indicator of the research productivity of the supervisor is an important determinant of the completion and dropout rates. However, this effect seems due to the fact that supervisors with a good research record attract and select better students. There is no evidence of an independent effect of having a supervisor who is an active researcher.

JEL Classification: C41, I21

Keywords: Duration analysis, education, graduate program

Jan C. van Ours

Tilburg University

Department of Economics

P.O. Box 90153

NL-5000 Tilburg

The Netherlands

Tel: 31134662316

Fax: 31134663042

Email:vanours@kub.nl 


\section{Introduction}

There have only been a few studies that give a detailed empirical analysis of the Ph.D. production process, and in particular Ph.D. completion rates. Bowen and Rudenstine (1992) utilize data on all entrants to graduate programs in six fields at ten major research universities in the US over a 25-year period. They show that there are differences in completion rates according to the type of financial support that students receive.

Booth and Satchell (1995) are interested in the determinants of withdrawals and successful completions of British Ph.D. students. Their motivation is a possible shortfall of trained researchers in the (near) future. They analyze data on about 500 entrants in Ph.D. programs in various fields, clustered in three categories: social sciences, arts and languages, and science and engineering. Using retrospective information on the 1980-entrants collected in 1986, they estimate a competing risks model with withdrawals and completions as outcomes. Among the explanatory variables are financial support from the research council and ability as measured by undergraduate scores. They find that neither the financial support, nor the ability variable affect the completion rate significantly. A variable that does influence thesis completion is the subject area, with arts and languages having lower completion rates and science and engineering higher completion rates than the social sciences. Furthermore, Ph.D. students who are studying part-time and Ph.D. students registered full time, but with a job, have lower completion rates.

Ehrenberg and Mavros (1995) have a similar reason for their study: in the US there are projections of a future shortage of $\mathrm{Ph}$.Ds. One of the potential policies to prevent this shortage is increased financial support for graduate students. Ehrenberg and Mavros use data on entrants over the period 1962-1986 in Cornell University's doctoral programs in economics, English, physics and mathematics. We only consider Ehrenberg and Mavros' results for the graduate program in economics. The analysis is based on the economic model of Breneman (1976) that focuses on the effects of academic labor market opportunities and financial support on graduate students. Improved labor market opportunities may induce students to shorten the time-to-degree. Also, the level and types of financial support influence the completion process: being a teaching assistant may leave less time for research, while being a research assistant may speed up the thesis.

The statistical model used by Ehrenberg and Mavros is the proportional hazards competing risks model with a flexible baseline hazard. This means that the hazard rate is assumed to be constant within time intervals, but is allowed to 
differ between time intervals. The explanatory variables are: having (not having) a master's degree at the time of first registration, gender, US (not US) citizen or permanent resident, ability (as measured by graduate record examination (GRE) test scores $(\mathrm{GREV}, \mathrm{GREM})^{1}$ ), financial support (specified as the proportion of a student's time spent as either a teaching assistant, a research assistant or financed by other sources), labor market opportunities (as specified by the mean starting salary for new assistant professors in the field, and by the percentage of new Ph.Ds in the field seeking employment in academia in the current academic year). Furthermore, a time trend is included to account for gradual changes in performance. Finally, some dummy variables are introduced to account for regime switches like a major change in the Ph.D.-requirements.

From the estimation results it appears that completion rates decrease with time spent as a teaching assistant. Dropout rates are lower, if, at the start of the program, a Ph.D. student had a master's degree or was not a US citizen or permanent resident. Ability, as measured by GRE and labor market conditions do not have a significant effect on the completion and dropout rates. According to the authors this may be due to the inaccuracy of the student ability measures and the inadequacy of the labor market indicators.

This paper studies outcomes for Dutch Ph.D. students in economics. We use data from three Dutch universities that have a joint Ph.D. program in economics. Our outcome variables are the duration until completion of the thesis and the duration until dropout. We investigate whether selection standards affect the completion and dropout rates and whether there is a correlation between the dropout and completion rate. A negative correlation in the sense that observed and unobserved variables have an opposite effect on the dropout and completion rate, would mean that $\mathrm{Ph}$.D. students who drop out would have needed more time than the average student to complete their thesis.

We also study the quality of the supervisor as a determinant of the completion and dropout rate. In The Netherlands Ph.D. students are assigned to a supervisor at the start of the program. The supervisor even has a decisive voice in the selection of the student. The rationale for this close tie between student and supervisor is the conventional wisdom that a good match ensures the timely completion of the thesis. Our results confirm the importance of the (research) ability of the supervisor. However, we distinguish between the effect of the selection and the effect of the supervision proper. If most of the supervisor effect is related to the quality of the supervision, the close tie between supervisor and student is important. However, if most of the effect is due to selection of able students,

\footnotetext{
${ }^{1}$ GREV $=$ verbal aptitude GRE score, GREM = mathematics aptitude GRE score
} 
high-quality supervisors should concentrate on the recruitment of students and need not supervise all of them.

Van der Ploeg (1996) has argued that dropout and late completion are due to inadequate supervision. The current system makes the student dependent. It gives little incentive to supervisors to minimize dropout and encourage timely completion. Graduate students who do not complete on time receive unemployment benefits that are paid by the university. The universities may lean on supervisors, but their leverage is limited. For this reason he proposes that the students who qualify for the Ph.D. program, select their supervisor. In this system supervisors who are perceived to provide low quality guidance, will not attract graduate students. It is based on the hypothesis that it is possible to identify good supervisors. We show that this may not be an easy task. In particular, our results show that 'certification' of supervisors based on their track record in research is not a guarantee for minimal dropout and timely completion. The apparent success of certified supervisors is due to their ability to attract and select high quality students. Because we find that, even after controlling for observed ability characteristics of students, there is a substantial unexplained variation in their dropout and completion rates, the key to low dropout and timely completion is selection rather than supervision. The current system of decentralized selection results in variation in selection standards. Supervisors who are not active researchers, are most likely unable to recognize the qualities that are needed to be a successful researcher. Our results downplay the importance of supervision and stress the importance of selection. Hence, Van der Ploeg's proposal will be an improvement if the freedom to choose one's supervisor will not deter, and preferably attract high ability students. The centralized selection that is implicit in his proposal may be better at maintaining high standards in selection. The matching of students and supervisors is less important.

This paper makes two econometric contributions. First, we show how to estimate the risk of an outcome, even if that outcome is never observed. Second, we test for endogeneity of a regressor in a rather complex competing risks model.

The paper is organized as follows. In section 2 we discuss the Ph.D. program in economics in The Netherlands. We also present the data that we use in our analysis. Section 3 discusses the statistical model and section 4 presents the estimation results. Section 5 concludes. 


\section{Ph.D. Program and Data}

\subsection{Graduate program}

The graduate program in The Netherlands has undergone a major overhaul in the late 1980s. Before the overhaul universities recruited junior faculty from the ranks of the MA graduates. Undergraduate education in The Netherlands is highly specialized, and at the time an undergraduate degree was about equivalent to a US MA degree. In addition to teaching, the junior faculty worked on their dissertation which they eventually did or did not complete. The supervision of this dissertation research was rather loosely organized. Full professors had an obligation to provide guidance, but the lack of a deadline did not put any pressure on the supervisor to ensure a timely completion of the thesis. Non-completion was not a reason for denial of tenure, although it precluded promotion to senior faculty positions.

In the 1980s higher education was restructured. First, the duration of (still specialized) undergraduate programs was limited to 4 years. As a consequence, the undergraduate degree was no longer a sufficient preparation for independent research. For that reason, a graduate program was established that in addition to the opportunity of research under the supervision of a (full) professor, provided additional education and training. In the new system, the Ph.D. student or AIO (Assistent In Opleiding) has a four year contract. In these four years he/she attends classes that are a preparation for independent research. The education component of the program lasts about one year. After this year the AIO works under supervision on a Ph.D. thesis. After four years the AIO is entitled to unemployment benefits for a maximum period of 18 months. If the Ph.D. student does not succeed in defending his/her thesis within four years, he or she has to finish the thesis while being unemployed or working in a regular job. The number of $\mathrm{Ph}$.D. students that enters the program each year is determined by a budget allocated to the graduate program by each university. The financial position of each Ph.D. is the same: AIOs receive a regular salary that is rather low at the start and increases during the contract period. Except for some teaching duties, their only obligation is to finish their thesis, preferably in 4 years. Although the organization of the graduate program is roughly the same over fields and universities, there are differences in the education component (graduate teaching did not exist before the overhaul) and supervision. In the sequel we restrict attention to three Dutch universities that have a joint Ph.D. program in economics. Economics should be interpreted in a broad sense, as econometrics, (a part of) operations research, and business economics are also covered by this program. 
Because AIOs have a regular job, the recruitment of new graduate students follows roughly the same procedure as the recruitment of new faculty. The main difference is the role of the supervisor of the prospective graduate student. If a number of AIO positions is vacant, there is a competition between potential supervisors who write research proposals. After an internal selection procedure some potential supervisors receive permission to hire a graduate student for a period of four years. To attract candidates usually an advertisement is placed in a national newspaper or magazine. Often candidates are also suggested by colleagues, or recent graduates of the recruiting university are approached. Candidates are screened by a committee and if they meet minimum requirements, the supervisor chooses among the candidates. The supervisor both selects and guides the student during the thesis research.

\subsection{Data}

From the administrative files of three Dutch universities we derived information concerning characteristics of the Ph.D. students and their supervisors. In our analysis we use information on $250 \mathrm{Ph}$.D. students who started before January 1, 1993. The closing date of our administrative files is January 1, 1998. After removing Ph.D. students who had a foreign ${ }^{2}$ undergraduate education or for whom not all relevant information could be extracted from the files, we have a sample of 200 Ph.D. students, who all have been exposed to the 'risks' of completion or dropout for more than 5 years. We excluded students with a foreign undergraduate degree, because foreign (and Dutch) Ph.D. applicants are not subjected to a standardized entrance test as in the US. Dutch undergraduate programs in a particular field are of comparable quality.

Figure 1 presents the cumulative completion and dropout probabilities during the program, i.e. the fraction of students who completed or dropped out at or before a particular point in time ${ }^{3}$. The time scale is the time in the program. It is seen that no Ph.D. student defends his or her thesis within three years, while a few students complete in three to four years. Most students finish in five to seven years after the start, and after seven years the fraction remains almost constant, i.e. there are few completions after seven years. Figure 1 also shows that already a few months after the start some Ph.D. students drop out. The dropping out continues until about four years, and after that year all students seem to stay on. This is due to the fact that after the end of the contract dropout is no longer

\footnotetext{
${ }^{2}$ At the time this was a small fraction of the starting graduate students.

${ }^{3}$ Note that the dropout probabilities are on the right axis and read top-down.
} 
registered. Students have little incentive to report that they will not finish their thesis.

For each Ph.D. student in the sample the administrative files contain information on: gender, duration of the undergraduate study, undergraduate degree at the university that employs the supervisor (or not), field of undergraduate degree, supervisor is a research fellow (or not). Although all undergraduate programs have a duration of four years, students receive financial support for five years. Because in The Netherlands it is possible to fail (even repeatedly), only students that pass (most of the) exams on the first occasion succeed in fulfilling the degree requirements in four years. Hence an indicator of the event that the degree was obtained in less than five years is an indicator of the ability and motivation of the student. If the undergraduate degree was granted by the same university that employs the supervisor, the supervisor may have more information on the ability of the student than can be obtained for an outside candidate. Moreover, the student may have started on the research project as an undergraduate. Both the better assessment and a possible headstart would have a positive effect on the thesis completion rate. Although undergraduate programs in a particular field are comparable between universities, students with an undergraduate degree in econometrics or mathematics are considered to be better prepared for the graduate program in economics. Although we have no detailed information on the track record of supervisors, we know whether they are a research fellow or not. Research fellows are chosen on the basis of their track record. Periodically, a joint committee of the three universities collects a list of publications of the faculty. If the quantity and quality of the publications meets a standard, the faculty member becomes a research fellow. Being a research fellow is mainly a honorary distinction, although it may make it easier to obtain a small research budget. Research fellows may be better supervisors, but as we noted, they may also select/attract better students. The Appendix gives the definition of all the variables.

The number of new hires in a particular year is determined by the number of vacant AIO positions and the success of the recruitment effort to fill these vacancies. Most Ph.D. positions are financed from a university budget. Some AIO positions are financed by the Netherlands Science Foundation (NWO). These positions are awarded in a national competition in which researchers propose projects. The research record of the prospective supervisor is even more important in the national competition than in the university one. The selection process of the externally funded AIO is the same as that of a university funded Ph.D. student. 
Our output indicators are the time to completion of the thesis, where completion coincides with the thesis defense ${ }^{4}$, and the time to dropout ${ }^{5}$. This choice of output indicators is dictated by the limitations of the administrative data, and the lack of information on outcomes after graduation or dropout, e.g. type of job, earnings etc. We assume that timely completion is preferred over late completion. This is certainly true for the universities that must pay the unemployment benefits after the expiration of the four year contract. Although the Ph.D. program does not have a selection phase, as in the US, early drop out is preferred over dropout just before or after the end of the contract. Moreover, those students should leave the program who would have needed a relatively long time to graduate. This is equivalent to a (large) negative correlation between the graduation and dropout rates, or opposite signs of the regression coefficients in the two hazard rates.

For a first impression of the effects of the explanatory variables we calculated the probability of completion or dropout after 5 years. Table 1 gives the results for different subsamples of Ph.D. students. The last column summarizes the composition of our sample. One in five students is female, one in three has finished the undergraduate study in less than 5 years, one in three has a mathematics or econometrics undergraduate degree, one in four has a degree from the university that employs their supervisor, two in five have a supervisor who is a research fellow.

The bottom row of the first three columns shows that $43 \%$ of the students finished their Ph.D. within 5 years, 20\% dropped out and 37\% had not completed their dissertation yet. The first three columns of Table 1 show the 5 year completion, dropout, and censored fractions for subgroups. Men, students who received their undergraduate degree in less than five years, students with an econometrics/mathematics degree, students who graduated from the supervisor's university, and students who have a research fellow as supervisor, have a higher completion probability. Note that the apparent negative correlation between the completion and dropout probabilities is a statistical artifact. Only when we consider the underlying hazards, can we study the relation between the completion and dropout processes.

Columns 4-6 give the completion, dropout, and censored fractions in the overall sample. It is difficult to interpret these numbers, because students are under observation for different periods. For some students we have information for a

\footnotetext{
${ }^{4}$ Due to an administrative delay the Ph.D. student will actually have finished the thesis some months before the defense.

${ }^{5}$ Remember that dropout is only registered adequately during the first four years.
} 
five years period, for others we have nine years of information. The differences have the same sign as in the columns 1-3, although they are generally smaller. The fractions in the fifth column are approximately the same as those in the second column indicating that most of the dropout occurs in the first five years.

Figure 2 gives the cumulative completion and dropout probabilities for the subsamples of students who are supervised by a research fellow or not. After 6 years the cumulative completion probability for students with a research fellow as supervisor is $81 \%$, while it is $43 \%$ for the other students. After 9 years the cumulative completion probabilities are $85 \%$ and $50 \%$, respectively. The difference in dropout probability is also substantial. After two years the students with a research fellow as supervisor have a dropout probability of $1 \%$, while this is $14 \%$ for the other students. After four years the probabilities are $3 \%$ and $22 \%$.

In Table 2 we contrast the characteristics of students who are and who are not supervised by a research fellow. The main differences are that research fellows prefer students who have a quantitative background and that they are more successful in attracting NWO funding. In the sequel we will use the latter distinction to test whether supervision by a research fellow speeds up completion and prevents dropout.

\section{Statistical model}

Our statistical model is similar to the competing risks model used by Ehrenberg and Mavros (1995). We assume that a Ph.D.-student faces two 'risks': one of completing the Ph.D., the other of dropping out. We investigate several alternative specifications. We start with a competing risks model in which, conditionally on the observed regressors, both transition rates are independent. Next, we allow for dependence between the risks by introducing unobserved differences between the students. We consider only the simplest form of unobserved heterogeneity that allows us to check whether there is a negative relation between the unobservables in the dropout and completion rates.

The completion rate at elapsed duration $t$ conditional on observed characteristics $x^{6}, \theta_{c}(t \mid x)$ has a proportional hazard specification:

$$
\theta_{c}(t \mid x)=\exp \left(v_{c}+x^{\prime} \beta_{c}+I_{c t}^{\prime} \gamma_{c}\right)
$$

\footnotetext{
${ }^{6}$ In addition to the variables presented in the Appendix we also use two university dummy variables to account for possible differences between the three universities. We are not allowed to report the coefficients of these two dummy variables.
} 
where $\beta_{c}$ is a vector of regression coefficients. The coefficient $v_{c}$ is a constant term. Duration dependence is specified as a step function such that the exit rate is constant within duration intervals and may differ between intervals: $I_{c t}$ is a vector of indicator variables for the duration intervals that take value 1 on specified annual duration intervals and value 0 otherwise, and $\gamma_{c}$ is a corresponding vector of coefficients. These coefficients give the relative change in the hazard in comparison to a reference interval (here the interval 3-4 years). The last duration interval is the open interval $6+$ years. Since there is no completion in the first three years, we set $\gamma_{c 1}=\gamma_{c 2}=\gamma_{c 3}=-\infty$, so that the completion hazard is 0 during the period $0-3$ years. Note that these would also be the Maximum Likelihood Estimates (MLE) of these parameters.

The dropout rate at elapsed duration $t$ conditional on observed characteristics $x, \theta_{d}(t \mid x)$ also has a proportional hazard specification:

$$
\theta_{d}(t \mid x)=\exp \left(v_{d}+x^{\prime} \beta_{d}+I_{d t}^{\prime} \gamma_{d}\right)
$$

where $\beta_{d}$ is a vector of regression coefficients and $v_{d}$ is a constant term.

Again, duration dependence is specified as a step function: $I_{d t}$ is a vector of indicator variables for the duration intervals. We assume that the hazard rate is constant during the period $0-4$ years, and again, be it at a different level, after 4 years.

The observations can be divided into three groups (remember that all students are followed for at least five years): dropouts during $[0,3]$ (in that interval the completion hazard is 0$), N_{1}$ observations, dropouts or completions in $[3,4]$ (both outcomes are possible), $N_{2}$ observations, and completions and rightcensored observations during $[4, \infty), N_{3}$ observations. After four years dropout is not registered. As we shall see, this complicates the analysis somewhat.

The contributions to the loglikelihood of the observations in the first two groups are easily determined. In the third group we only observe completions. If a student drops out after 4 years, it will appear as if he or she is still in the program at the end of the observation period. Hence, the censored observations comprise of students who are still working on their thesis, at the time of censoring and of students who have dropped out after 4 years in the program, but before the time of censoring. These are non-overlapping groups, and the likelihood contribution is the sum of the probabilities of the corresponding events.

If $d=1$ if the outcome is completion and $d=0$ if it is dropout, and $c=0$ if the duration is censored, then the loglikelihood is 


$$
\begin{aligned}
& \log L={ }_{i=1}^{X^{1} 1} \ln \theta_{d}\left(t_{i} \mid x_{i}\right) e^{-\mathrm{R}_{\mathrm{t}_{\mathrm{i}}}} \theta_{\mathrm{d}}\left(s \mid x_{\mathrm{i}}\right) d s^{\circ}+ \\
& +{ }_{i=1}^{X^{2}} \ln \theta_{c}\left(t_{i} \mid x_{i}\right)^{d_{\mathrm{i}}} \theta_{d}\left(t_{i} \mid x_{i}\right)^{1-d_{\mathrm{i}}} e^{-\mathrm{R}_{\mathrm{t}_{\mathrm{i}}}\left(\theta_{\mathrm{c}}\left(s \mid x_{\mathrm{i}}\right)+\theta_{\mathrm{d}}\left(s \mid x_{\mathrm{i}}\right)\right) d s^{\jmath}}+ \\
& +{ }^{X^{3}} c_{i} \ln \theta_{c}\left(t_{i} \mid x_{i}\right) e^{-\mathrm{R}_{\mathrm{t}_{\mathrm{i}}}\left(\theta_{\mathrm{c}}\left(s \mid x_{\mathrm{i}}\right)+\theta_{\mathrm{d}}\left(s \mid x_{\mathrm{i}}\right)\right) d s^{2}}+ \\
& +{ }_{i=1}^{\mathrm{X}_{3}}\left(1-c_{i}\right) \ln _{4}^{\cdot \mathrm{Z}_{t_{\mathrm{i}}}} \theta_{d}\left(t \mid x_{i}\right) e^{-\mathrm{R}_{\mathrm{t}}\left(\theta_{\mathrm{c}}\left(s \mid x_{\mathrm{i}}\right)+\theta_{\mathrm{d}}\left(s \mid x_{\mathrm{i}}\right)\right) d s} d t
\end{aligned}
$$

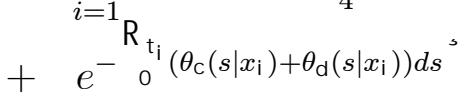

By censoring all observations after 4 years, it is seen that the regression coefficients in the completion and dropout hazard and also the baseline hazard for both intensities during these years can be estimated. The estimation of the baseline hazards for the completion and dropout rates after 4 years is more problematic, because we do not observe dropouts. To understand why we are able to estimate the dropout hazard, even if we do not observe dropouts, consider the case that all observations are in group 3, the completion and dropout hazards are constant over time and over students, observation starts a time 0 (instead of after 4 years), and that there is no censoring. The MLE of the hazards are then given by

$$
\begin{aligned}
& \hat{\theta}_{c}=\frac{N_{c}}{N_{c}+N_{n c}} P \frac{N_{c}}{N_{c} t_{i}} \\
& \hat{\theta_{d}}=\frac{N_{n c}}{N_{c}+N_{n c}} \stackrel{N_{c}}{N_{i=1}^{N_{c}} t_{i}}
\end{aligned}
$$

with $N_{c}, N_{n c}$ the number of Ph.D. students who, respectively, complete and not complete their thesis. Of course, in this case we eventually learn which students have dropped out. The MLE of $\theta_{c}$ if completion were the only outcome is multiplied by the probability that completion comes before dropout to obtain the MLE of $\theta_{c}$ and with the probability that dropout comes before completion to obtain the MLE of $\theta_{d}$. The estimate of the dropout hazard is derived from the fraction of observations that never completes. The empirical distribution of the durations is defective: a fraction of the students never completes the thesis and has an infinite spell until completion.

To allow for (conditional) dependence of the completion and dropout rates, we introduce unobserved differences between the students. In particular, we want to 
allow for the fact that students that have a low completion rate (for reasons not known to us), have a high dropout rate, and the other way around. The simplest specification that allows for this, distinguishes between two types of students with constants in the dropout and completion rates equal to $v_{d 1}, v_{c 1}$ and $v_{d 2}, v_{c 2}$ and with the fraction of type 1 students equal to $p$. Efficient dropout, as defined above, corresponds to (without loss of generality we assume $v_{d 1}>v_{d 2}$ ) $v_{c 1}<v_{c 2}$.

The loglikelihood is (we denote integrals of the hazard rates by capital letters, and we use a subscript $i$ to indicate dependence on $x_{i}$ )

$$
\begin{aligned}
& \log L={ }_{i=1}^{\mathrm{X}_{1}} \ln p v_{d 1} \theta_{d i}\left(t_{i}\right) e^{-\Theta_{\mathrm{di}}\left(t_{\mathrm{i}}\right) v_{\mathrm{d} 1}}+(1-p) v_{d 2} \theta_{d i}\left(t_{i}\right) e^{-\Theta_{\mathrm{di}}\left(t_{\mathrm{i}}\right) v_{\mathrm{d} 1}} \\
& +{ }^{X^{2}} \ln p\left(v_{d 1} \theta_{d i}\left(t_{i}\right)\right)^{1-d_{\mathrm{i}}}\left(v_{c 1} \theta_{c i}\left(t_{i}\right)\right)^{d_{\mathrm{i}}} e^{-\Theta_{\mathrm{di}}\left(t_{\mathrm{i}}\right) v_{\mathrm{d} 1}-\Theta_{\mathrm{ci}}\left(t_{\mathrm{i}}\right) v_{\mathrm{c} 1}}+ \\
& i=1 \quad \text { i } \\
& +(1-p)\left(v_{d 2} \theta_{d i}\left(t_{i}\right)\right)^{1-d_{\mathrm{i}}}\left(v_{c 2} \theta_{c i}\left(t_{i}\right)\right)^{d_{\mathrm{i}}} e^{-\Theta_{\mathrm{di}}\left(t_{\mathrm{i}}\right) v_{\mathrm{d} 2}-\Theta_{\mathrm{ci}}\left(t_{\mathrm{i}}\right) v_{\mathrm{c} 2}}+ \\
& +{ }_{i=1}^{\mathrm{X}_{3}} c_{i} \ln p v_{c 1} \theta_{c i}\left(t_{i}\right) e^{-\Theta_{\mathrm{di}}\left(t_{\mathrm{i}}\right) v_{\mathrm{d} 1}-\Theta_{\mathrm{ci}}\left(t_{\mathrm{i}}\right) v_{\mathrm{c} 1}}+ \\
& +(1-p) v_{c 2} \theta_{c i}\left(t_{i}\right) e^{-\Theta_{\mathrm{di}}\left(t_{\mathrm{i}}\right) v_{\mathrm{d} 2}-\Theta_{\mathrm{ci}}\left(t_{\mathrm{i}}\right) v_{\mathrm{c} 2}}+ \\
& +{ }_{i=1}^{X^{X_{3}}}\left(1-c_{i}\right) \ln _{4}^{\cdot \mathbf{Z}_{t_{\mathrm{i}}} \mathrm{n}} p v_{d 1} \theta_{d i}(t) e^{-\Theta_{\mathrm{di}}(t) v_{\mathrm{d} 1}-\Theta_{\mathrm{ci}}(t) v_{\mathrm{c} 1}}+ \\
& +\quad(1-p) v_{d 2} \theta_{d i}(t) e^{-\Theta_{\mathrm{di}}(t) v_{\mathrm{d} 2}-\Theta_{\mathrm{ci}}(t) v_{\mathrm{c} 2}} \mathrm{O} d t+ \\
& +p e^{-\Theta_{\mathrm{di}}\left(t_{\mathrm{i}}\right) v_{\mathrm{d} 1}-\Theta_{\mathrm{ci}}\left(t_{\mathrm{i}}\right) v_{\mathrm{c} 1}}+(1-p) e^{-\Theta_{\mathrm{di}}\left(t_{\mathrm{i}}\right) v_{\mathrm{d} 2}-\Theta_{\mathrm{ci}}\left(t_{\mathrm{i}}\right) v_{\mathrm{c} 2}}
\end{aligned}
$$

The identification of the parameters is as before.

\section{Estimation results}

\subsection{Parameter estimates}

The estimation results are given in Table 3. The first column shows the results for the competing risks model without unobserved heterogeneity. In the completion rate the coefficients of the study duration indicator and home degree are different from zero at conventional levels of significance. Students who have a degree from their supervisor's university have a significantly higher completion rate. The same is true for students who obtained their undergraduate degree in less than five years who complete their graduate studies faster. Surprisingly, they also have a higher dropout rate. There is significant duration dependence in the 
completion rate with the rate being lowest in the fourth year, higher from 4 to 6 years, and decreasing again after 6 years. In the dropout hazard only the coefficient of research fellow is significantly different from zero. Students with a research fellow as supervisor have a dropout rate that is only $12 \%$ of the dropout rate of students that do not have a research fellow as supervisor. Note that many regression coefficients have opposite signs. In particular, the coefficients that are significantly different from 0 , except the study duration indicator, have opposite signs. Hence, dropout mainly removes students with characteristics that make them unlikely to finish their thesis on time, with the exception of students who completed their undergraduate degree without delay.

The second column of Table 3 shows the estimation results when we allow for two types of students. These types are not observed, but inferred from the data. While the difference in the completion rates of both groups is small, their dropout rates differ substantially. The group with the lower completion rate has the higher dropout rate and the group with the higher completion rate has a dropout rate that is not distinguishable from zero. The dropout due to unobservables is indeed efficient. There are about as many lower and higher quality students. Note that all coefficients are somewhat larger if we allow for unobserved differences.

Students who have a research fellow as supervisor are not doing better in terms of completion rates but there is a substantial difference in the dropout rate. In the third and fourth column we consider the question whether research fellows are better at supervising $\mathrm{Ph}$. D. students than non-fellows, or whether they are better at attracting able students. In other words, we decompose the large and highly significant effect of supervision by a research fellow into a selection effect and a supervision effect. We use two estimation methods to decompose the effect: a test using an instrumental variable and selection on unobservable type.

We already noted (see Table 2) that research fellows are more successful in obtaining external (NWO) funding for Ph.D. positions. The indicator of NWO funding is a potential instrumental variable that affects the probability that an AIO is supervised by a research fellow, but has no direct effect on the completion or dropout rate. The first condition can be verified by estimating a linear probability model for the research fellow indicator on the included

explanatory variables in the model and the external funding indicator. The regression coefficient of the latter indicator is 0.40 (with robust standard error 0.13). The second condition can not be verified from the data, but it is likely to be satisfied given the similar nature of the national and university competition for projects and the equal selection process for AIOs. The national competition clearly favors researchers with a strong track record, and one might suspect 
that the quality of the proposals in the national competition is higher. If a better proposal increases the completion and decreases the dropout rate, we would expect significantly positive and negative coefficients on this variable in the corresponding hazards. Because the potentially biased coefficients in column 2 are positive and negative, respectively, using the predicted value of the regression of the research fellow indicator on the explanatory variables and the NWO funding indicator, would leave a positive and negative coefficient in the completion and dropout hazards. The results reported in the third column of Table 3 show that the coefficient becomes essentially zero in the dropout hazard and even reverses sign (but remains insignificant) in the completion hazard. Hence, if NWO funded AIOs work on more promising projects than this implies that supervision by a research fellow has a negative effect on the completion and a positive effect on the dropout rate. Note that we use the instrument only to test for a zero research fellow effect. This corresponds to an Intention to Treat (ITT) test. Estimation of a nonzero effect is complicated, because the IV estimator for competing risks models has not been developed (Bijwaard and Ridder (1999) make a first attempt).

In the second estimation method, we concentrate on selection on unobservable type. In particular, we assume that the fraction $p$ of able students (type 2 students with a low dropout rate and a high completion rate) differs between research fellows and non-fellows. Column 4 reports the estimates. Research fellows only supervise high-ability students, whereas the fraction for non-research fellows is .56. Apparently, research fellows are better in attracting able students. This confirms the conclusion that the research fellow effect is due to selection of able students. Note that the model in column 4 fits even better than the model in column 2 (with the same number of parameters).

To illustrate the differences between the two types of graduate students and to indicate the importance of selection, we use the estimates of column 4 of Table 2 to compare the dropout and completion of the two types of students. For a male Ph.D. student, with an undergraduate degree in economics that was obtained in less than 5 years at the university of his supervisor, we calculate cumulative completion and dropout rates in case this student is a high-ability type and in case he is a low ability type. The results are shown in Table 4. After four years $25 \%$ of the high-ability students has completed there dissertation, while only $1 \%$ has dropped out. After five years the cumulative completion rate is $81 \%$, after six years $97 \%$. Columns three and four of Table 4 shows the cumulative completion rates and dropout rates in case the student with the same observable characteristics is a low-ability type student. Now, the completion rates 
are much lower and the dropout rate is substantially higher. After four years $26 \%$ of the low-ability students has dropped out, while only $3 \%$ has completed their dissertation. Even after eight years only $42 \%$ of the low-ability students has finished their dissertation. After 15 years $54 \%$ of the low-ability students has finished their dissertation while the remaining $43 \%$ has dropped out. This can be taken as the final outcome.

\section{Conclusions}

This paper presents an analysis of the failure and completion rates of graduate students in economics at three universities in The Netherlands. The students leave the "Ph.D.-production process" either because of completion of their thesis or because they quit and thus dropout. We investigate the determinants of the duration until completion of the thesis and the duration until dropout. Our analysis is complicated by the fact that after four years dropout is not registered. In the paper we show that we can estimate the dropout rate after four years, even if dropout itself is never observed in this time period.

In theory, early dropout is preferred over dropout just before or after the end of the contract. Moreover, dropout is efficient if those students leave the program who would have needed a relatively long time to graduate. We find that to a large extent this is the case. The coefficients of many of the observed characteristics have opposite signs in the two hazards rates, and the unobservables in the two hazards are negatively correlated.

An important determinant of the Ph.D. production process, both empirically and from a policy perspective, is whether the supervisor is a research fellow or not. Being a research fellow is an indicator of the track record of the supervisor in research. We find that the apparent effect of supervision by a research fellow on the dropout/completion rates is due to selection of high ability students and not to superior supervision. We also find that the difference in performance between high and low ability students is large. It has been argued by Van der Ploeg (1996) that the dependence of the graduate student on his or her supervisor should be reduced. Insofar his proposal creates uniform(ly high) selection standards, it may indeed increase the completion and decrease the dropout rate. Less should be expected from supervision by researchers with a proven track record in research.

Although our conclusions are specific to graduate education in The Netherlands, the methodology can be used to study completion and dropout rates in other countries, and in particular, the distinction between the effect of structural features of the programs and the effect of selection into these programs. 


\section{References}

B ij waard, G. and G. Ridder (1999) Correcting for selective compliance in a re-employment bonus experiment, Amsterdam/Rotterdam, Tinbergen Institute W orking Paper.

B o ot h, A.L. and S.E. Sat chell (1995) 'The Hazards of Doing a Ph.D.: An Analysis of Competition and Withdrawal Rates of British Ph.D. students in the 1980's', J ournal of the Royal Statistical Society A, 158, 297-318.

B ow en, W .G ., and N.L. R udenst ine (1992) In Pursuit of the Ph.D., Princeton, NJ, Princeton University Press.

B r eneman, D.W . (1976) 'The Ph.D. Production Process', in: Fromkin, J.T., D.T. Jamison and R.Radner (eds.) Education as an Industry, Cambridge, MA, Ballinger.

Ehrenber g, R.G . and P.G. M avros (1995) 'Do Doctoral Students' Financial Support Patterns Affect their Times-to-Degree and Completion Probabilities?', J ournal of Human Resources, 30, 581-609.

Van der Ploeg, R (1996) 'Ph.D. student too dependent on supervisor' (in Dutch: Promovendus te afhankelijk van hoogleraar), Volkskrant, 15 januari. 


\section{A ppendix: Definition of variables}

Female: dummy variable with value 1 if the $\mathrm{Ph} . \mathrm{D}$. student is female and 0 if male.

Study $<5$ years: dummy variable with value 1 if the undergraduate study took less than 5 years and 0 otherwise.

Home degree: dummy variable with value of 1 if the Ph.D. student has an undergraduate degree of the university of the supervisor and 0 otherwise.

Research fellow: dummy variable with value 1 if the Ph.D. student has a research fellow as supervisor and value 0 otherwise.

Econometrics: dummy variable with value 1 if the Ph.D. student has an undergraduate degree in econometrics or mathematics and 0 otherwise.

Duration until completion: period of time (in years) between entry in the Ph.D. and the date of the thesis defense.

Duration until dropout: period of time (in years) between entry in the Ph.D. program and the date that the Ph.D. student quitted the program. 
Table 1 Fraction graduated, dropped out and right censored after 5 years and in sample (\% of subgroup)

\begin{tabular}{|c|c|c|c|c|c|c|c|}
\hline \multirow[b]{2}{*}{ Variable } & \multicolumn{3}{|c|}{ After 5 years } & \multicolumn{3}{|c|}{ Sample } & \multirow[b]{2}{*}{ Tota } \\
\hline & Grad. & Out & Cens. & Grad. & Out & Cens. & \\
\hline Female & 31 & 31 & 38 & 52 & 32 & 16 & 22 \\
\hline Male & 47 & 17 & 36 & 69 & 18 & 13 & 78 \\
\hline Study $<5$ years & 54 & 20 & 26 & 66 & 20 & 14 & 33 \\
\hline Study $\geq 5$ years & 38 & 20 & 42 & 65 & 21 & 13 & 67 \\
\hline Econometrics & 56 & 13 & 32 & 76 & 13 & 11 & 32 \\
\hline Other field & 37 & 23 & 39 & 61 & 25 & 15 & 68 \\
\hline Home degree & 50 & 18 & 32 & 69 & 19 & 12 & 59 \\
\hline Other university & 33 & 23 & 44 & 60 & 24 & 16 & 41 \\
\hline Research fellow & 53 & 5 & 42 & 88 & 5 & 6 & 39 \\
\hline Not fellow & 37 & 30 & 34 & 51 & 31 & 18 & 61 \\
\hline Total & 43 & 20 & 37 & 66 & 21 & 14 & 100 \\
\hline
\end{tabular}


Table 2 Characteristics of students supervised by a research fellow or not (\%)

\begin{tabular}{|l|ccc|}
\hline & Research fellow & Not fellow & A verage \\
\hline Female & 21 & 23 & 22 \\
Study $<$ 5years & 37 & 30 & 33 \\
Econometrics & 53 & 18 & 32 \\
Home degree & 58 & 60 & 59 \\
External funding & 13 & 3 & 7 \\
\hline
\end{tabular}


Table 3 Maximum Likelihood Estimates for various specifications (t-values)

\begin{tabular}{|c|c|c|c|c|}
\hline & Obs. & Unobs. & ITT & Unobs. + \\
\hline \multicolumn{5}{|l|}{ Completion hazard } \\
\hline Female & $-0.07(0.2)$ & $-0.37(1.0)$ & $-0.05(0.2)$ & $-0.28(0.8)$ \\
\hline Study $<5$ years & $0.45(2.0)$ & $0.54(1.9)$ & $0.63(2.4)$ & $0.35(1.5)$ \\
\hline Econometrics & $0.30(1.3)$ & $0.30(1.0)$ & $0.51(2.3)$ & $0.26(1.0)$ \\
\hline Home degree & $0.45(2.0)$ & $0.62(2.1)$ & $0.44(2.0)$ & $0.51(2.2)$ \\
\hline Research fellow & $0.30(1.3)$ & $0.58(1.7)$ & $-1.08(1.1)$ & - \\
\hline \multicolumn{5}{|l|}{ Duration dependence } \\
\hline $4-5$ years & $1.57(6.3)$ & $1.73(6.0)$ & $1.58(6.3)$ & $1.60(6.4)$ \\
\hline $5-6$ years & $2.05(6.7)$ & $2.40(5.1)$ & $2.10(6.5)$ & $2.13(7.0)$ \\
\hline $6+$ years & $1.57(2.7)$ & $2.01(2.9)$ & $1.45(2.4)$ & $1.58(2.8)$ \\
\hline$v_{c 1}$ & $-2.61(4.8)$ & $-3.46(3.8)$ & $-2.19(3.6)$ & $-4.06(3.4)$ \\
\hline$v_{c 2}$ & $-2.61(4.8)$ & $-2.28(3.7)$ & $-2.19(3.6)$ & $-2.10(3.7)$ \\
\hline \multicolumn{5}{|l|}{ Dropout hazard } \\
\hline Female & $0.58(1.7)$ & $0.96(1.8)$ & $0.42(1.2)$ & $0.90(1.6)$ \\
\hline Study $<5$ years & $0.54(1.5)$ & $0.62(1.3)$ & $0.58(1.7)$ & $0.65(1.4)$ \\
\hline Econometrics & $0.00(0.1)$ & $0.13(0.2)$ & $-0.56(1.3)$ & $0.17(0.3)$ \\
\hline Home degree & $-0.30(0.9)$ & $-0.50(1.2)$ & $-0.39(1.2)$ & $-0.49(1.1)$ \\
\hline Research fellow & $-2.13(3.6)$ & $-2.57(3.6)$ & $-0.40(0.2)$ & - \\
\hline \multicolumn{5}{|l|}{ Duration dependence } \\
\hline $4+$ years & $0.73(1.5)$ & $0.72(1.0)$ & $0.52(0.9)$ & $-0.04(0.0)$ \\
\hline$v_{d 1}$ & $-3.30(5.7)$ & $-2.89(3.6)$ & $-3.28(3.6)$ & $-2.73(3.4)$ \\
\hline$v_{d 2}$ & $-3.30(5.7)$ & $-\infty$ & $-3.28(3.6)$ & $-5.93(4.8)$ \\
\hline$p$ & - & $0.53(4.9)$ & - & - \\
\hline$p$ (non-fellow) & - & - & - & $0.44(4.7)$ \\
\hline$p$ (fellow) & - & - & - & 0.00 \\
\hline$-\ln L$ & 335.7 & 333.7 & 348.4 & 332.9 \\
\hline
\end{tabular}


Table 4 Cumulative completion and dropout probabilities (\%) of high and low ability types ${ }^{a}$

\begin{tabular}{|l|c|c|c|c|}
\hline & \multicolumn{2}{|c|}{ High-ability } & \multicolumn{2}{c|}{ Low-ability } \\
\cline { 2 - 5 } & Completion & Dropout & Completion & Dropout \\
\hline 4 years & 25 & 1 & 3 & 26 \\
5 years & 81 & 1 & 16 & 31 \\
6 years & 97 & 1 & 31 & 34 \\
7 years & 98 & 1 & 37 & 36 \\
8 years & 99 & 1 & 41 & 38 \\
\hline 15 years & 99 & 1 & 43 & 54 \\
\hline
\end{tabular}

a) Male student with undergraduate degree in less than 5 years, degree in economics from supervisor's university. 
Figure 1 Cumulative completion and dropout probabilities

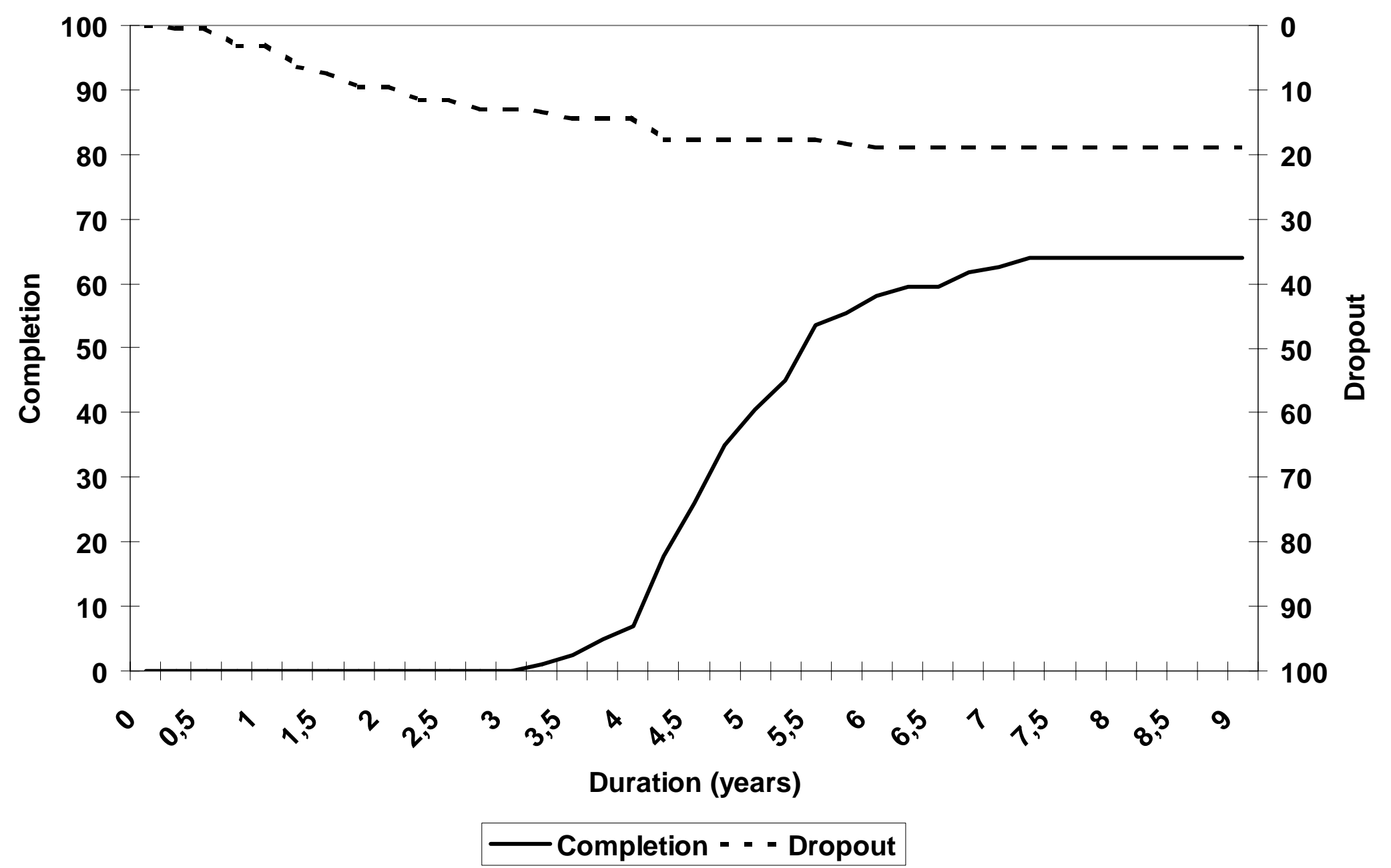


Figure 2 Cumulative Completion and dropout probabilities; research fellows and non-research fellows

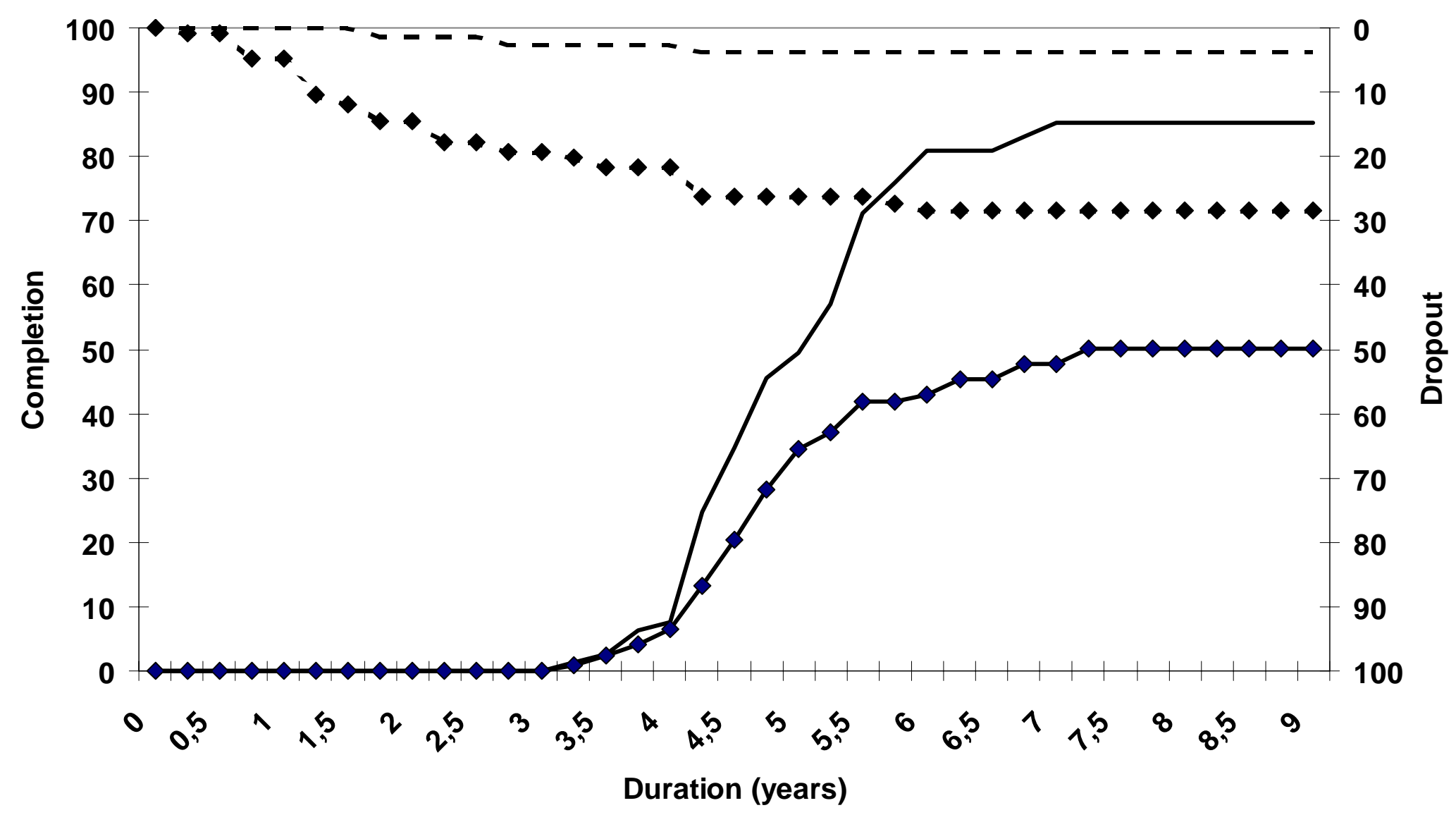

$\longrightarrow$ compl fellow $\neg$ compl non-fellow - - - dropout fellow - $\bullet$ dropout non-fellow 